Glick, Douglas (1996). A reappraisal of Brown and Levinson's Politeness: Some universals of language use, eighteen years later. Semiotica 109:141-71.

Silverstein, Michael, \& Urban, Greg (1996). Natural histories of discourse. Chicago: University of Chicago Press.

(Received 5 March 2004)

Language in Society 35 (2006). Printed in the United States of America DOI: $10.1017 /$ S0047404506220347

\title{
The discursive approach to polite behavior: A response to Glick
}

\author{
Miriam A. Locher \\ Department of English Languages and Literatures, \\ University of Berne \\ 3000 Berne 9, Switzerland \\ locher@ens.unibe.ch
}

In his review of Power and politeness in action: Disagreements in oral communication (2004), Douglas J. Glick raises two important points: (i) the issue of identifying politeness in language, and (ii) the ideological framework employed in language analysis. Before explicating my understanding of politeness, I need to clarify that in chap. 5 on disagreements, as Glick has noted, I do indeed focus on linguistic strategies to express different points of view without discussing politeness. For example, I deliberately refrain from labeling strategies such as boosting or hedging as more or less polite. In other words, I do not wish to imply that I have already witnessed manifestations of politeness by simply identifying hedged utterances (or indirectness), nor that I have witnessed impoliteness by identifying unmitigated linguistic strategies (or directness). In this way, my approach to politeness differs significantly from the more classical view, initiated by Brown \& Levinson 1987 and followed by many others, which equates mitigation with politeness and directness with impoliteness. Conversely, in my understanding, I use "mitigation" as a purely technical term, and I make no claim that any given linguistic form is inherently polite or impolite.

With the knowledge gained about the linguistic strategies employed to express disagreement by the interactants of my data, I proceeded to the second level of analysis, in which I look at relational work and offer "close readings." I use the latter term for the process of interpretation that looks at the interaction turn by turn in order to discuss its dynamics. This process is necessarily the researcher's reinterpretation of what happened. I explicitly leave open the possibility for a (limited) number of alternative readings, which must be informed by the theoretical framework proposed. My definition of politeness also leaves open the possibility for different perceptions (2004:91):

Politeness for the speaker: A polite utterance is a speaker's intended, marked and appropriate behavior which displays face concern; the motivation for it 
lies in the possibly, but not necessarily, egocentric desire of the speaker to show positive concern for the addressees and/or to respect the addressees' and the speaker's own need for independence.

Politeness for the addressee: Addressees will interpret an utterance as polite when it is perceived as appropriate and marked; the reason for this is understood as the speaker's intention to show positive concern for the addressees' face and/or the speaker's intention to protect his or her own face needs.

What is important to stress here is that there is no guarantee that what one speaker intends to be (im)polite is also perceived to be (im)polite by the recipient. Although this statement may hark back to the more general wisdom that a message sent is not necessarily a message received, it is nevertheless crucial to recognize this for the level of relational work involved in language. Far too often in the aftermath of Brown \& Levinson's theory, entire populations have been labeled "positive" or "negative politeness" cultures, on the basis of equating linguistic strategies on a one-to-one basis with politeness. What is meant and perceived as polite in a given context, however, will depend on judgments of appropriateness and markedness. These judgments are based on cultural knowledge of NORMS of appropriateness, and these are - as we all know constantly changing. This understanding of politeness is further developed in Locher \& Watts 2005, where we call it "the discursive approach to politeness" and stress that there is an ongoing struggle over forms of appropriateness in any given group of people over time.

In my analysis of language in use, I wished to move away from a clear-cut dichotomy between polite and impolite behavior, and in particular to leave open the interpretation for behavior that is considered unmarked and neither polite nor impolite. This latter interpretation is rarely available in the literature on politeness, most of which automatically treats everything that is not polite as impolite. In my close readings, therefore, I attempted to look for markedness and offered INTERPRETATIONS of possible instances in my data that may be OPEN to an interpretation of politeness by the interactants.

The second issue that I would like to address briefly is Glick's concern about the ideologies that we as researchers impose on our work. I agree that it is crucial that the framework employed is made clear from the very beginning (see my theoretical chapters). It is equally important to read others' work with an open and critical mind, perhaps to detect ideological underpinnings that might not have been discussed enough. But at the end there is no neutral, non-ideological way of approaching language studies or even of using language in any context for any purpose. Our own education and training and who we are will always have an impact on the way we conduct our research. The best we can do is to be as transparent as possible and to acknowledge our own limitations in this respect.

At the end of his review, Glick raises these questions: "Is the goal of our analysis to model what we think politeness is? Is it to predict what others think it 
is? Why?" For my own research, I can state that it is not my aim to impose my own culturally dependent understanding of politeness on others, nor is it possible to predict IN GENERAL what others may think politeness is, for the reasons mentioned above. I strongly believe, however, that an approach to politeness that is aware of the discursive nature of this phenomenon and nevertheless tries to find evidence of it in minute analysis of natural data can illuminate language in use and constitute a first step in moving politeness research away from simply equating linguistic form with social function.

\section{REFERENCES}

Brown, Penelope, \& Levinson, Stephen C. (1987). Politeness: Some universals in language usage. Cambridge: Cambridge University Press.

Locher, Miriam A. (2004). Power and politeness in action: Disagreements in oral communication. Berlin: Mouton de Gruyter.

, \& Watts, Richard J. (2005). Politeness theory and relational work. Journal of Politeness Research 1:9-33.

(Received 26 October 2005)

Language in Society 35 (2006). Printed in the United States of America DOI: $10.1017 /$ S0047404506230343

Aneta Pavlenko \& Adrian Blackledge (eds.), Negotiation of identities in multilingual contexts. Clevedon, UK: Multilingual Matters, 2004. Pp. 312. $\mathrm{Hb} \$ 44.95$.

$$
\begin{array}{r}
\text { Reviewed by SYLVIE RoY } \\
\text { Faculty of Education, University of Calgary } \\
\text { Calgary, Alberta Canada T2N 1N4 } \\
\text { syroy@ @ ucalgary.ca }
\end{array}
$$

This is one of the best books I have read this year. The topic is up to date and relevant for many contexts. Each author contributes to the originality of this edited book. The editors, Pavlenko \& Blackledge, have done a wonderful job in putting together a series of texts that demonstrate how negotiation of identities is embedded within larger socioeconomic, sociohistoric and sociopolitical contexts. In order to situate their own framework, the editors start by examining different approaches to the negotiation of identities in multilingual contexts. The sociopsychological approach examines the negotiation of identities in second language learning and language use. However, this approach treats learning trajectories as linear and unidirectional, with little acknowledgment of the fact that learning language and identity building are more complex. Interactional sociolinguistics focuses on the negotiation of identities via code-switching and language choice. This approach sees social identities as more fluid and constructed through linguistic and social interaction. However, even though much sociolinguistic research examines the negotiation of languages choices and identities in

Language in Society 35:5 (2006) 